Subscriber access provided by CIC BIOMAGUNE

\title{
Article
}

\section{Size-dependent transport and cytotoxicity of mitomycin-gold nano-particle conjugates in 2D and 3D mammalian cell models}

Isabel García, Malou Henriksen-Lacey, Javier Calvo, Dorleta

Jimenez de Aberasturi, Manuel M Paz, and Luis M. Liz-Marzán

Bioconjugate Chem., Just Accepted Manuscript • DOI: 10.1021/acs.bioconjchem.8b00898 • Publication Date (Web): 19 Dec 2018

Downloaded from http://pubs.acs.org on December 20, 2018

\section{Just Accepted}

"Just Accepted" manuscripts have been peer-reviewed and accepted for publication. They are posted online prior to technical editing, formatting for publication and author proofing. The American Chemical Society provides "Just Accepted" as a service to the research community to expedite the dissemination of scientific material as soon as possible after acceptance. "Just Accepted" manuscripts appear in full in PDF format accompanied by an HTML abstract. "Just Accepted" manuscripts have been fully peer reviewed, but should not be considered the official version of record. They are citable by the Digital Object Identifier (DOI®). "Just Accepted" is an optional service offered to authors. Therefore, the "Just Accepted" Web site may not include all articles that will be published in the journal. After a manuscript is technically edited and formatted, it will be removed from the "Just Accepted" Web site and published as an ASAP article. Note that technical editing may introduce minor changes to the manuscript text and/or graphics which could affect content, and all legal disclaimers and ethical guidelines that apply to the journal pertain. ACS cannot be held responsible for errors or consequences arising from the use of information contained in these "Just Accepted" manuscripts. 


\section{Size-dependent transport and cytotoxicity of mitomycin-gold nanoparticle conjugates in 2D and 3D mammalian cell models}

Isabel García, ${ }^{\dagger}$ Malou Henriksen-Lacey, ${ }^{\S}$ Javier Calvo,§ Dorleta Jimenez de Aberasturi, ${ }^{\dagger}$ Manuel M. Paz, ${ }^{*}$ and Luis M. Liz-Marzán ${ }^{*} § \perp$

\footnotetext{
${ }^{\dagger}$ Biomedical Research Networking Center in Bioengineering Biomaterials and Nanomedicine, CIBER-BBN, 2014, Donostia-San Sebastián

${ }^{\S}$ CIC biomaGUNE, Paseo de Miramón 182, 20014 Donostia-San Sebastián, Spain.

‡ Departamento de Química Orgánica, Facultade de Química, Universidade de Santiago de Compostela, 15782 Santiago de Compostela, Spain

${ }^{\perp}$ Ikerbasque, Basque Foundation for Science, 48013 Bilbao, Spain

Supporting Information Placeholder
} 
ABSTRACT: This work aims at learning how the size of gold nanocarriers influences the transport of DNA-alkylating antitumoral drugs. For this purpose, we devised conjugates of mercaptoethylmitomycin C (MEMC), a DNA alkylating agent, with gold nanoparticles of different sizes $(2,5$ and $14 \mathrm{~nm})$, and studied how size affects drug cytotoxicity, tumor penetrability, cellular uptake and intracellular localization using twodimensional (2D) and three-dimensional (3D) cell models. We show that only small, $2 \mathrm{~nm}$ nanoparticles can transport MEMC efficiently to the cell nucleus, whereas MEMC cell uptake is much lower when delivered by these small nanoparticles than with the larger ones. 3D cellular models showed that smaller nanoparticles can transport MEMC towards deeper areas of tumor spheroids as compared to larger nanoparticles. We discuss the insights of this work towards the efficient delivery of DNA-targeting drugs.

\section{INTRODUCTION}

One of the current strategies toward improving therapeutics for cancer treatment involves the use of nanoparticles as carriers to selectively deliver anticancer drugs to tumor cells. ${ }^{1}$ Drug-delivering nanoparticles can increase the intracellular concentration of drugs in cancer cells relative to normal cells, thereby reducing the extent of side effects, while enhancing anticancer properties with respect to the free drug. Additionally, drugs delivered on nanoparticles usually present longer circulation times than the free drug, a property that improves the efficacy of drugs that are metabolized quickly. Among various drug delivery platforms, gold nanoparticles $\mathrm{CAu}$ NPs) offer several advantages as carriers, as they are non-toxic, non-immunogenic, and present long circulation times. ${ }^{2-5}$ Other attractive features of $\mathrm{Au}$ NPs include their tunable physicochemical properties, high stability in buffer solutions when a proper coating is included, narrow size distribution and useful optical properties. ${ }^{6}$ As evidence of the therapeutic viability of drug delivery by $\mathrm{Au}$ NPs, PEGylated Au NPs conjugated to a tumor necrosis factor (TNF) are currently undergoing clinical trials. ${ }^{7}$

It has been reported that the size of Au NPs influences their intracellular localization, which may have important consequences in drug delivery efficiency. ${ }^{8-11}$ of particular interest, $\mathrm{Hu}$ and Liang showed that only nanoparticles with a hydrodynamic size smaller than the $9 \mathrm{~nm}$ diameter of the nuclear pore complex, can be transported to the cell nucleus. ${ }^{8}$ For PEGylated nanoparticles attached to a fluorescent ligand, this size restriction meant that only small nanoparticles with a $2 \mathrm{~nm}$ core diameter could reach the nucleus. Gold nanoparticles linked to doxorubicin, a DNA intercalating agent, by a nonexcisable amide bond, were shown to reach the nucleus only when their size was smaller than $2.7 \mathrm{~nm}^{12}$

Based on the reports discussed above, we hypothesized that size should have a significant effect on the biological activity of nanoparticles carrying antitumor drugs that exert a cytotoxic activity through DNA modification. These include DNA alkylating agents (nitrogen mustards, nitrosoureas, aziridines) and those from the platinum family, which together constitute a significant portion of the chemotherapeutic options used in the clinic. ${ }^{13}$ DNA alkylating agents are (or can be activated to be) electrophiles and, therefore, they can be rapidly inactivated in the cytoplasm by reaction with water or with thiols, such as glutathione. ${ }^{14}$
Therefore, the cytotoxic activity of DNA-alkylating agents should be improved when these agents are delivered by nanoparticles that are small enough to reach the cell nucleus. The alkylating agent would then be unloaded from the small NPs close to DNA, its target nucleophile, thereby producing a high level of cytotoxic lesions. On the other hand, larger $\mathrm{Au}$ nanoparticles would release the drug in the cytoplasm, and only a small fraction of the cargo would be able to reach the target in the nucleus, thereby decreasing their efficacy as drug delivery systems. To test this hypothesis we selected 7mercaptoethylmitomicyn C (MEMC, 3), a mitomycin derivative that contains a sulfhydryl group (Scheme 1B), as a DNA alkylating agent. Mitomycins are a family of antitumor antibiotics ${ }^{15}$ that form covalent monoadducts and crosslinks with DNA upon activation by reduction of the quinone ring (Scheme 1A). ${ }^{16}$ One member of the mitomycin family, mitomycin C (MMC, Scheme 1A and Scheme S1) is currently used clinically in the chemotherapy of several cancers, but still with a modest efficacy, ${ }^{15}$ mainly because of a short half-life in humans around 45 min. ${ }^{17}$ That DNA is the major biological target of is illustrated by the fact that the formation of one single MMC-induced crosslink lesion is enough to cause the death of a bacterial cell. ${ }^{18}$ In order to alkylate DNA, mitomycins must be activated by reduction, a reaction that generates a short-lived intermediate, in the range of microseconds for MMC semiquinone radical (one-electron reduction) and 15 seconds for MMC hydroquinone (two-electron reduction). ${ }^{19}$ The intermediate that alkylates DNA is derived from the hydroquinone form of $\mathrm{MMC}$, but this compound is mostly converted to a non-cytotoxic metabolite. ${ }^{20}$ Therefore, if the reduction of mitomycins occurs in the cytoplasm, a detoxification pathway is activated but if the drug is delivered to the cell nucleus, then the detoxification pathway should be reduced, increasing its cytotoxicity. It has been shown that cells overexpressing mitomycin-activating enzymes in nuclear localizations are more sensitive to the cytotoxic effects of MMC than those overexpressing the enzymes in the endoplasmic reticulum ${ }^{21}$ or in mitochondria, ${ }^{22}$ evidence for the potential benefits of transporting mitomycins to the nucleus.

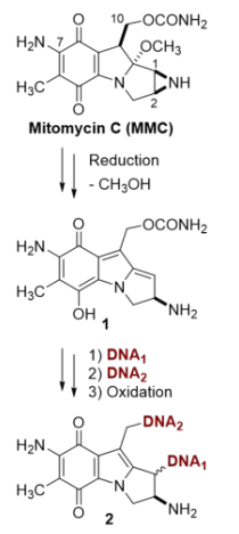

в
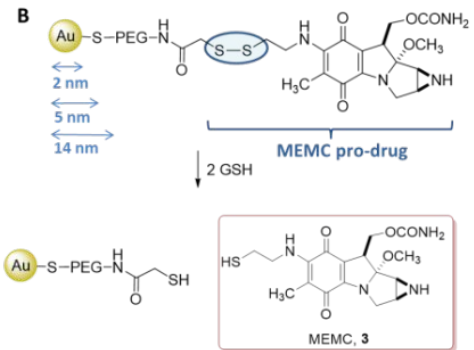

C
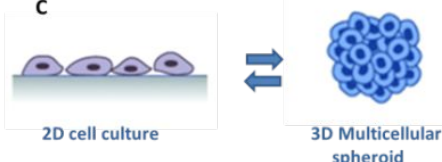

Scheme 1. A) Mechanism for the bis-alkylation of DNA by mitomycin $\mathrm{C}$ to form DNA crosslinks. B) Schematic representation of MEMC pro-drug nanoformulation, to be validated in 2D and 3D cellular models (C).

We report here the synthesis and biological activity of gold nanoparticles bearing MEMC, covalently linked to the nanoparticles by an excisable disulfide bond. The glutathionetriggered reduction of the disulfide bond should allow selective drug release after cell internalization (Scheme 1B). We assessed how the size of Au NPs conjugates affects cytotoxicity, 
drug uptake, tumor penetrability and cellular localization, using both 2D and 3D cell culture models (Scheme 1C).

\section{RESULTS AND DISCUSSION}

For DNA-targeting drugs, the transport events that occur after a drug carrier is administered to an organism can be summarized in 5 stages: (1) plasma circulation and accumulation in tumors; (2) transport through the tumor blood vessels to the interstitial matrix where proliferating cells are located; (3) diffusion through the interstitial space; (4) cellular internalization and (5) transport from the cytoplasm to the cell nucleus. The ideal size for efficient delivery of drugs by NPs varies for the multiple stages of nanoparticle transport that take place in the organism after they are administered. ${ }^{23} \mathrm{We}$ want to analyze how size affects the three latter stages of the transport of MEMC, a DNA-alkylating agent, by gold nanoparticles.

Design of a MEMC prodrug incorporating a glutathionesensitive linker

Three reasons weighed in selecting MEMC (compound 3) as the mitomycin derivative for the synthesis of Au NP conjugates: (i) it contains a thiol group, which facilitates the synthesis of releasable drug conjugate; (ii) it is highly cytotoxic, as demonstrated by the pharmacological activity of several prodrugs of MEMC (e.g. KW-2149 and BMS-181174, EC0225, Figure S1); ${ }^{24-28}$ (iii) it has been shown to form DNA crosslinks with no need for an enzymatic reduction, likely because it can be activated by an internal redox reaction between the thiol and the quinone. ${ }^{29}$ This latter property renders MEMC especially interesting for this work because, should successful delivery to the cell nucleus be achieved, then the activation of the drug into a DNA-alkylating intermediate would not depend exclusively on the presence of reducing enzymes at that specific cellular location.

Linking drugs onto carriers by disulfide bonds is a well-known strategy toward thiol-activated intracellular drug release, ${ }^{29}$ because thiol concentrations are dramatically higher inside the cell than at extracellular locations (in the case of glutathione, 1,000 - 10,000 fold higher). ${ }^{3}$ Therefore, the disulfide bond in Au NP-MEMC conjugates should be stable in the extracellular environment, but efficiently cleaved upon internalization of the nanoparticles by cells, thereby releasing the free drug (Figure 1B). This strategy has been previously demonstrated for $\mathrm{Au}$ NPs linked by a disulfide bond to the fluorescent dye HSBDP. ${ }^{31}$ In our synthetic design we decided to couple amino-terminated gold nanoparticles with the carboxylate-substituted MEMC derivative 5 (Scheme 2), rather than the reverse alternative (an amino-substituted mitomycin with carboxylate-terminated nanoparticles). The main reason for this choice was that the required amino-terminated mitomycin derivative is unstable. ${ }^{33}$ An added advantage of this coupling approach is that the cellular uptake of cationic nanoparticles is more efficient than the uptake of anionic ones. ${ }^{32}$

Synthesis of Au-MEMC conjugates and characterization of drug release

$\mathrm{Au}$ NPs were prepared with three different average core diameters $(2.2 \pm 0.7,4.7 \pm 0.7$ and $14.7 \pm 1.6 \mathrm{~nm})$, using established methodologies ${ }^{34-36}$ (see Experimental). The NPs were capped with self-assembled monolayers of $\mathrm{HS}_{-} \mathrm{PEG}_{2000^{-}}$ $\mathrm{NH}_{2}$, using a sufficient excess ( $>20$ fold) of the thiolated ligand to ensure surface saturation and the same PEG densities for all the conjugates. The resulting amino-functionalized $\mathrm{Au}$ NPs were then washed to remove non-bound ligands. Aminemodified $\mathrm{Au}$ NPs are known to display enhanced cellular uptake and NP penetration and allow further conjugation, ${ }^{37}$ while the PEG component is expected to reduce serum protein adsorption. ${ }^{38}$ MEMC was then incorporated through derivative 5 (Scheme 2), which bears a terminal carboxylate group that can be used to create an amide bond with the amine groups at $\mathrm{Au} @ \mathrm{PEGNH}_{2}$ NPs. Compound 5 was synthesized following a method previously used to prepare other mitomycin C-(N7)substituted disulfides. ${ }^{39}$ In short, mitomycin A was treated with 2-(2-pyridyldithio)ethylamine hydrochloride in $\mathrm{MeOH}$ to yield the mixed disulfide 4 , which was then treated in situ with sodium thioglycolate, to obtain 5 (see Figures S2-S5), with a 55\% overall yield for the two steps (Scheme 2).

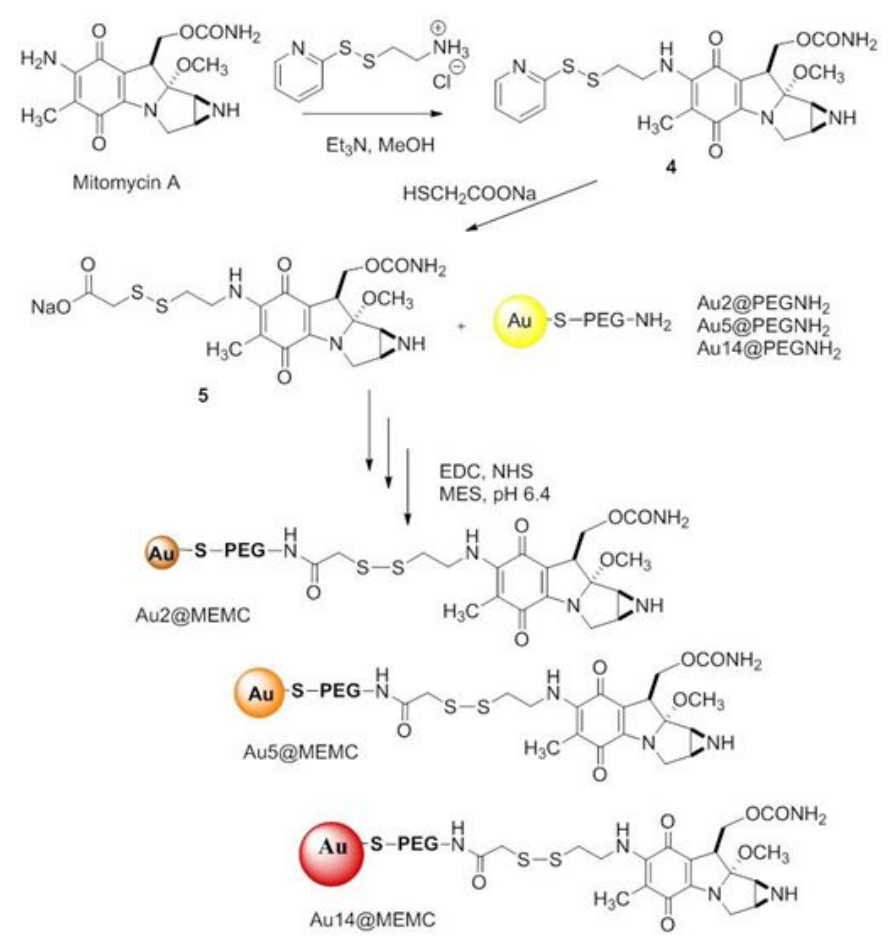

Scheme 2. Synthesis of Au nanoparticles conjugated to MEMC.

The carboxylate group of 5 was activated by treatment with a carbodiimide and $\mathrm{N}$-hydroxysuccinimide, and the resulting $\mathrm{N}$ hydroxysuccinimidyl ester was then coupled to Au@PEGNH ${ }_{2}$. Purification by centrifugation was monitored by analyzing (UVvis) the presence of the characteristic chromophore in $5(\lambda \max$ $376 \mathrm{~nm}$ ) in the filtrates. We found that non-covalently bound 5 could be efficiently removed from Au5@MEMC and Au14@MEMC by repeated washing with water. Although uncoupled 5 remained tenaciously bound to Au2@MEMC NPs when washing with water, it could be removed by using $50 \%$ methanol in water.

The recorded UV-Vis spectra correlate with the size and monodispersity of the Au@MEMC NPs, featuring a red-shift with increasing NP size ( $\lambda \max 507,518$ and $522 \mathrm{~nm}$ ). Representative TEM images for all three NPs with different diameters are shown in Figure 1. Drug payload in Au@MEMC conjugates was determined by differential UV-Vis spectroscopy, using the characteristic absorption band of 5, centered at 376 $\mathrm{nm}$ (SI, Figure S6), to determine the concentration of MEMC loaded onto the Au NPs. The resulting UV-Vis spectrum for Au2@MEMC was essentially identical to that of 5, whereas for 
Au5@MEMC and Au14@MEMC the subtracted spectra were distorted due to the stronger contribution of the nanoparticle cores to the absorbance, but they clearly showed an absorbance band with a maximum at $376 \mathrm{~nm}$ that could be used to calculate the drug payload (SI, Figure S7). The presence of this chromophore indicates that the mitomycin core remained intact after the coupling reaction, as potential side reactions of mitomycins would result in aromatization to an indolequinone ring, causing a hypsochromic shift in $\lambda_{\max }$ of about $50 \mathrm{~nm}$. All Au@MEMC NPs were water-soluble, colloidally stable, and with no signs of aggregation. Importantly, all nanoparticles were positively charged, with zeta-potential values ranging between +10 and $+16 \mathrm{eV}$ (Table S1). Although MEMC conjugation resulted in partial neutralization of cationic amino groups, zeta potential was still positive for Au@MEMC NPs. Thus, the main difference between the various conjugates used in our study was the particle size.
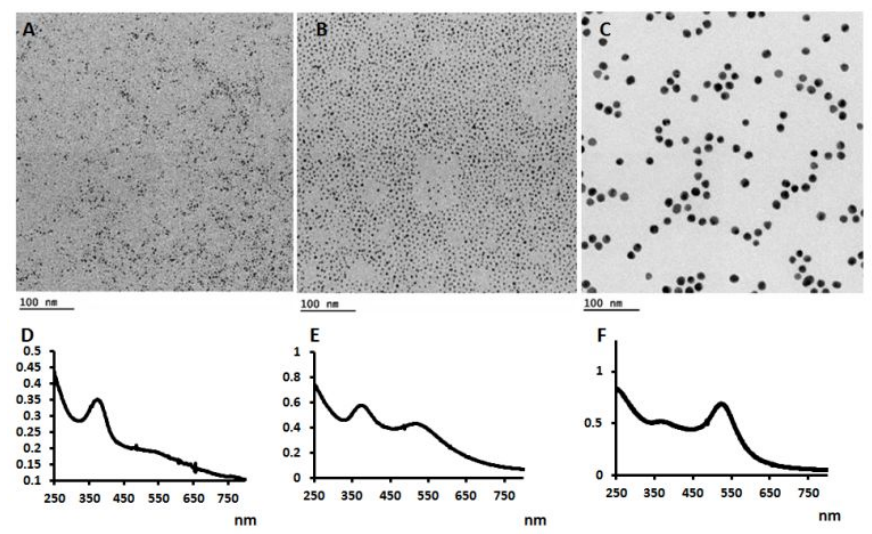

Figure 1. (A-C) Representative TEM images of Au@MEMC NPs, with average core diameters of $2 \mathrm{~nm}(\mathrm{~A}), 5 \mathrm{~nm}$ (B) and $14 \mathrm{~nm}$ (C). (D-F) UV-Vis spectra of Au@MEMC NPs $(2,5,14 \mathrm{~nm}$ for D, E, F) showing the characteristic mitomycin peak at $376 \mathrm{~nm}$ and the corresponding surface plasmon resonance band for the larger NPs.

We next investigated the reduction-triggered drug release from Au@MEMC conjugates. Release of MEMC (or its metabolites) was confirmed under reducing conditions (dithiothreitol (DTT), glutathione (GSH), or tris(2carboxyethyl)phosphine (TCEP)), using liquid chromatography coupled to mass spectrometry (LC-MS). Two major compounds were observed in the chromatograms obtained from samples of the three different nanoparticles treated with DTT (SI, Figure S8), which were identified as oxidized DTT and MEMC (SI, Figures S9, S10). Unfortunately, released MEMC could not be used to quantify drug payload due to its instability (Scheme S2), as revealed from control experiments using 5 and DTT. Interestingly, the amount of oxidized DTT detected in the HPLC chromatograms correlated with the relative drug payloads, as previously determined by UV-Vis analysis (SI, Figure S11, Table S2). This was an unexpected result because, in the presence of air, DTT should have oxidized to a similar extent in all samples. The presence of $\mathrm{Au}$ NPs thus appears to inhibit DTT oxidation, an observation that was not further investigated in this work. MEMCconjugated Au NPs treated with GSH or TCEP yielded complex HPLC chromatograms (SI, Figures S12, S13), as was also the case in control experiments where 5 was reduced with either GSH or TCEP. We tentatively propose structures for several compounds, which are compatible with ESI-MS data for some of the peaks observed (SI, Figures S13, S14). The presence of an indolequinone core in these compounds indicates that MEMC forms active metabolites upon release from the NPs by treatment with GSH or TCEP, thus demonstrating that MEMC does not require an enzymatic reduction to be converted to an alkylating species. Also, the formation of MEMC derivatives substituted by GSH or TCEP at the alkylating carbons (C1 and C10) after the reduction reactions discussed above evidences that the coupling reaction used to prepare Au@MEMC conjugates did not affect aziridine and carbamate groups in MEMC.

Cytotoxicity, uptake and cellular localization of Au@MEMC NPs in $2 \mathrm{D}$ cell cultures

We first investigated the cytotoxic efficacy of MEMC, either as a free drug (in the form of MEMC disulfide) or bound to Au NPs, against cells grown in standard 2D cultures. We used human dermal fibroblasts (HDF) and a human breast adenocarcinoma cell line (MDA.MD.231). As expected, Au NPs not carrying MEMC were non-toxic to both cell lines, within the tested range of concentrations (SI, Figure S15). Only a small decrease in MDA.MB.231 cell viability was noted upon exposure to the highest concentration of Au2@PEGNH ${ }_{2}$. For Au@MEMC nanocarriers, concentration-dependent cytotoxicity was observed, but we could not determine a clear effect of NP size. MDA.MB.231 cells were found to be more sensitive than HDF cells, at all Au@MEMC concentrations and Au NP sizes, with cell death reaching $70 \%$ of the total cell number when exposed to $2.5 \mu \mathrm{M}$ of Au14@MEMC (SI, Figure S15). This was only a marginal increase (3\%) over (MEMC)2, the disulfide form of MEMC (Figure S1), as a control compound.

At first glance, the negligible effect of nanoparticle size on the cytotoxicity of MDA.MB.231 cells appears to invalidate the original hypothesis of this work. However, a different picture emerges when the size-dependent uptake of MEMC is taken into consideration. We studied the relationship between cytotoxicity and MEMC uptake in order to learn how NP size influences the cytotoxicity of Au@MEMC conjugates after they enter the cell. The cellular uptake of MEMC was determined by factoring in the number of nanoparticles internalized per cell and the average number of MEMC molecules carried by nanoparticles of different sizes. Cell uptake of Au NPs was assessed by determining $\mathrm{Au}$ concentration in the cells by quantitative ICP-MS measurements, as previously reported. ${ }^{40}$ The results indicate a direct correlation between the number of internalized nanoparticles and their size (SI, Figure S16). This outcome agrees with previous reports that showed an increasing uptake efficiency of cationic gold nanoparticles for larger particle sizes. ${ }^{32,41}$ Also ICP-MS analysis of healthy HDF cells treated with Au@MEMC showed higher uptake for the larger Au14@MEMC nanoparticles than for smaller conjugates (SI, Figure S17). For both cell lines, NP uptake could be inhibited by using chemical endocytosis inhibitors (Figure S18). The results collectively revealed that multiple endocytic pathways are involved in the uptake of the different sized NPs and that these inhibitors worked more efficiently with the MDA.MB.231 cancer cell line. The average number of MEMC molecules per nanoparticle was calculated by deconvoluting the UV-Vis spectra of each Au@MEMC conjugate into two components: gold core and MEMC. With this data in hand, we determined the uptake of MEMC that each NP size provides, finding that it increased by roughly one order of magnitude with each particle size increment (Table 1 and Table S3). We then calculated the quotient between the cytotoxicity and the amount of MEMC internalized by the cells, and the results were 
normalized to determine the relative cytotoxicity per internalized MEMC (Table 1).

Table 1. Relative cytotoxicity of differently sized nanoparticles in MDA.MB.231 cells, normalized to MEMC uptake. An arbitrary value of 1 was assigned to $14 \mathrm{~nm}$ nanoparticles. The number of MEMC molecules internalized was calculated using the measurements of nanoparticle cell uptake by ICP-MS (Figure S16) and the calculation of drug payload (see Experimental). IC50 was determined from data shown in Figure S15.

\begin{tabular}{|c|c|c|c|}
\hline $\begin{array}{c}\text { Core } \\
\text { size } \\
\text { (nm) }\end{array}$ & $\begin{array}{c}\text { MEMC internalized } \\
\text { per cell (nmol) }\end{array}$ & $\begin{array}{c}\text { IC }_{\mathbf{5 0}} \\
(\boldsymbol{\mu} \mathbf{M})\end{array}$ & $\begin{array}{c}\text { Relative cytotoxicity } \\
\text { per internalized } \\
\text { MEMC }\end{array}$ \\
\hline $\mathbf{2}$ & 0.56 & 4.0 & 21 \\
\hline $\mathbf{5}$ & 6.25 & 2.4 & 3 \\
\hline $\mathbf{1 4}$ & 47.7 & 1.0 & 1 \\
\hline
\end{tabular}

The marked influence of nanoparticle size on MEMC uptake does not translate into a reciprocal effect on cytotoxicity: while MEMC uptake rises by 10 -fold with each NP size increment, cytotoxicity only increases by 2 -fold (Table 1 ). To summarize these observations when the cytotoxicity is normalized to MEMC uptake, $2 \mathrm{~nm}$ nanoparticles are 20 times more potent than $14 \mathrm{~nm}$ nanoparticles. The most plausible explanation for the observed discrepancy between uptake and cytotoxicity is that $2 \mathrm{~nm}$ nanoparticles are able to reach the cell nucleus, whereas larger $14 \mathrm{~nm} \mathrm{Au}$ larger nanoparticles are not. In order to confirm this we measured the nuclear and non-nuclear fractions of endocytosed NPs via ICP-MS, and supported the findings with TEM observations. Quantitative ICP-MS data on the localization of Au2, Au5 and Au14 NPs in MDA.MB.231 cells showed that Au2 NPs can effectively reach the cell nucleus, representing approximately $25 \%$ of all NP found in the cell (Figure 2). The slightly larger Au5 NPs can also reach the nucleus albeit in lesser amounts. We were unable to detect Au14 nm in the nucleus. This peri-nuclear or cytoplasmic location of Au5 and Au14 NPs was also observed via TEM imaging, although unfortunately we could not detect Au2 NPs due to limitations in the resolution of our TEM (SI, Figure S19). However, by applying a silver growth technique commonly used for the detection of small Au NPs in immunostaining techniques, we could successfully image the presence of $2 \mathrm{~nm}$ NPs in both nuclear and cytoplasmic locations (SI, Figure S19).

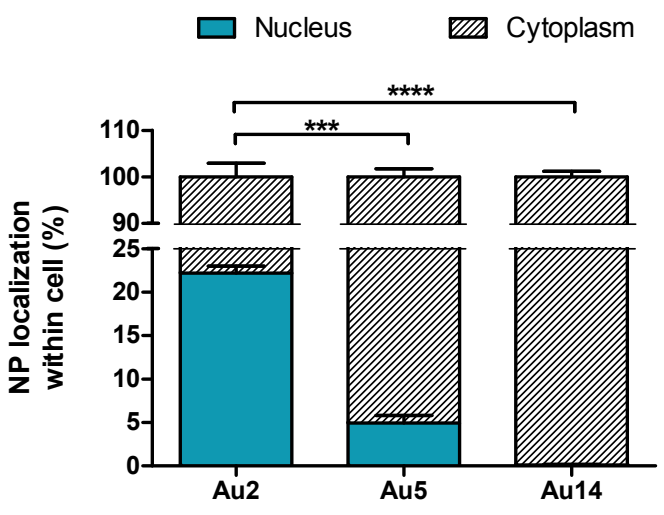

Figure 2. Localization of Au2, Au 5 and Au14 NPs in the nuclear and non-nuclear fractions of MDA.MB.231 cells. Cells were exposed to the NPs $(0.5 \mu \mathrm{M})$ for $6 \mathrm{~h}$, followed by treatment with the NE-PER Nuclear and Cytoplasmic Extraction Kit and ICP-MS analysis. Statistical testing (1-way ANOVA with Tukey post-test) shown is representative for both nuclear and cytoplasmic fractions $\left({ }^{* * *} \mathrm{p} \leq 0.001,{ }^{* * * *} \mathrm{p} \leq 0.0001\right)$.

Our findings are in agreement with previous research on cell nuclear penetration as a function of NP size. For example, the DNA-intercalating agent doxorubicin ${ }^{12}$ and a triplex-forming oligonucleotide ${ }^{8}$ were attached to the NPs by a non-excisable amide bond and, therefore, the DNA-targeting compounds could only hit their target when attached to NP conjugates capable of entering the nucleus. We can therefore assume that the ability of the Au2@MEMC nanoparticles to enter the nucleus will result in release of their DNA-targeting payload in close proximity to its target. This would explain why they show a level of cytotoxicity comparable to larger Au14 NPs, despite their strongly reduced cellular drug uptake. Larger Au14@MEMC nanoparticles dramatically increase drug uptake but, being unable to transport their payload to the nucleus, will release MEMC in the cytoplasm, where most of it will be inactivated by reacting with cytoplasmic nucleophiles or being converted into inactive reduced metabolites. ${ }^{20}$

Cytotoxicity, penetrability, uptake and localization of Au@MEMC in 3D spheroids

We next used multicellular tumor spheroid models to analyze the influence of nanocarrier size on the activity of Au@MEMC conjugates. Spheroid tumor models are spherical aggregates of tumor cells designed to reproduce the architecture of tumor tissue in vivo. ${ }^{42,43}$ Tumor spheroids are considered as a more accurate antitumor drug evaluation platform because they may allow us to test the capacity of the drug to navigate the interstitial space prior to reaching the proliferating cancer cells, a factor that cannot be analyzed when monolayer cell cultures are used. Testing the tumor penetrability of nanomedicines is particularly relevant because particle size may affect their ability to reach the inner, hypoxic regions of the tumor where proliferating cells are located. ${ }^{44}$ Spheroids are regarded as a bridge between monolayers and animal models, ${ }^{42}$ or even as a potential substitute for the latter. ${ }^{43}$

We used a 3D heterologous spheroid culture comprising both HDF and MDA.MB.231 cells. The incorporation of fibroblasts in spheroids has been shown to produce a more realistic in-vivo tumor model, as they support the growth of cancer cells via production of soluble factors and improving tumor-stroma interactions. ${ }^{44,45}$ We used low cell attachment round-bottomed plates, resulting in spheroids exhibiting sizes that could be controlled by varying the initial cell number and/or the incubation time (Figure S20). As noted in previous studies, ${ }^{46}$ the use of such plates produced spheroids with a suitable size for microscopy studies.

MDA.MB.231:HDF spheroids $\left(-350 \mu \mathrm{m}^{2}\right)$ were exposed to $\mathrm{Au} @ \mathrm{MEMC}$ conjugates, at a final drug concentration of $0.5 \mu \mathrm{M}$, for $48 \mathrm{~h}$. This concentration was chosen because it did induce some cytotoxicity in the $2 \mathrm{D}$ cell culture, but not so much that differences between formulations would go unnoticed. The extent of cytotoxicity caused by the Au@MEMC conjugates was determined by means of a live/dead fluorescence microscopy kit and a luminescence cell viability kit (see Experimental for details). Confocal fluorescence microscopy images of live/dead stained cells allowed us to calculate a corrected total fluorescence (CTF) value (Figure 4A, Figure S21A), representative of the fluorescence intensity in the spheroid for 
a given fluorophore and at a given z-height in confocal mode. We analyzed the CTF of the "dead" cell marker at the same zheight for all spheroids and confirmed that exposure of spheroids to Au NPs without MEMC did not cause any increase in cell death, as compared to control spheroids (Figure S21A), showing CTF values in the range between $3 \times 10^{7}$ and $5.5 \times 10^{7}$ a.u. In contrast, addition of Au@MEMC or (MEMC) 2 caused an increase in the detected values of the "dead" cell marker, and CTF values increased to $9.5-17 \times 10^{7}$ a.u. To ensure that the increase in fluorescence signal was not due to differences in spheroid size, the area at the given z-height was measured and shown to be similar for all samples (see SI, Figure S21B). The experiments were repeated using the luminescence cell viability kit, with similar results. Exposure of spheroids to drug-free nanoparticles did not affect cell viability, as indicated by high luminescence values, whereas Au@MEMC and compound 5 significantly decreased the luminescence readout (Figure 3B). Whilst in this instance a moderate but nonsignificant size-dependent behavior was noted, when we repeated the experiment with larger spheroids of approximately $600 \mu \mathrm{m}$ this size-dependent effect was more pronounced (SI, Figure S22).
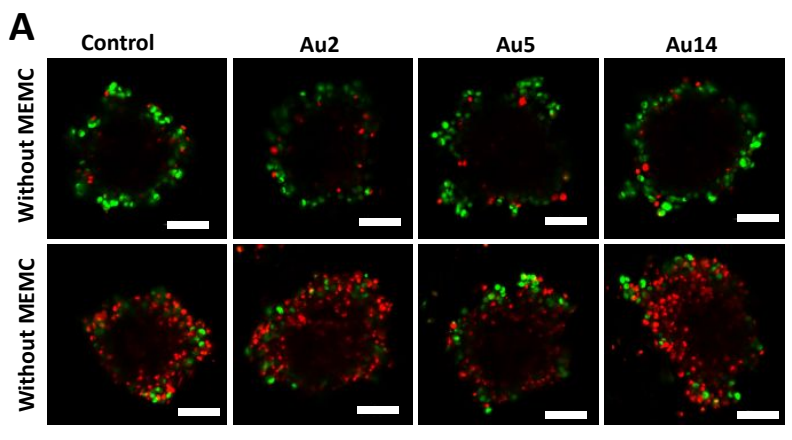

B

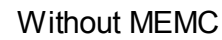

With MEMC

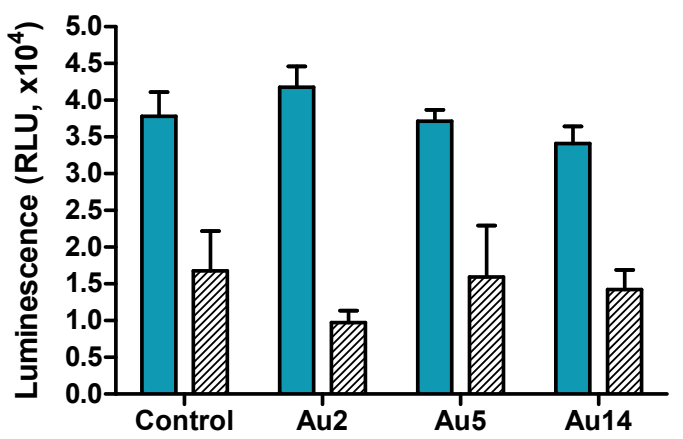

Figure 3. (A) Live/dead staining of MDA.MB.231:HDF spheroids showing the penetration of cytotoxic MEMC, delivered with or without NPs (final MEMC concentration was $0.5 \mu \mathrm{M}$ with a $48 \mathrm{~h}$ exposure to spheroids). Images were taken at the same z-height in the spheroid. Dead cells stain red due to the uptake of "dead cell fluorophore". Live cells stain green due to the presence of a cell permeable "live cell fluorophore", which is not expressed in dead cells. (B) Cell viability of spheroids incubated with nanoparticles, with and without MEMC, measured using the 3D-Glo luminescence viability assay (Promega). Statistical testing (2-way ANOVA with Bonferroni post-test) showed all MEMC-containing conditions to be significantly different $(\mathrm{p} \leq 0.0001)$ to their non-MEMC containing counterpart.

We finally carried out a detailed investigation of the ability of $\mathrm{Au}$ NPs with different sizes to penetrate into the cell spheroid volume. We therefore quantified confocal reflectance microscopy images (see details in SI, Figure S23) and supported our findings with transmission electron microscopy of ultramicrotomed sections from the spheroids. Spheroids were incubated with Au@MEMC nanocarriers for $48 \mathrm{~h}$ and a confocal microscope in reflection detection mode ${ }^{47,48}$ was used to obtain confocal images of the spheroids at the same z-height. A $633 \mathrm{~nm}$ laser line was used, and light reflected by the presence of Au NPs was captured by the detector, which could be treated and quantified in the same way as fluorescence intensity or darkfield microscopy images usually are. We used a self-developed macro in ImageJ $@$ to calculate the distance from the outer edge in which the reflection intensity decreases significantly, based on Gaussian Curve fitting (see Experimental for further details). As can be seen in Figure S23B, we registered a size-dependent effect on the penetration depth, the smallest nanoparticles reaching a depth of approximately $70 \mu \mathrm{m}$ from the spheroid outer edge, whereas the larger $14 \mathrm{~nm}$ nanoparticles could penetrate down to approximately $40 \mu \mathrm{m}$.

To validate these results, we measured the maximum nanoparticle penetration distance within the spheroids using TEM analysis. The limited resolution and contrast of the technique for this type of samples allowed us to obtain a reliable analysis for the spheroids exposed to the $14 \mathrm{~nm}$ and 5 $\mathrm{nm}$ NPs, but not for the ones exposed to $2 \mathrm{~nm}$ NPs. For the largest NPs (Au14@MEMC) we can readily detect the presence of Au NPs inside cells located in the outer $30 \mu \mathrm{m}$ rim, but as we move further inside the spheroid a lower number of nanoparticles was detected (Figures 3A, S24, S25). These results are in good agreement with our reflection measurements (Figure S23) and previously reported data. ${ }^{9}$ In this work we used cationic NPs bound to the DNA-alkylating drug by an excisable bond that is cleaved after the NP conjugates enter the cell, releasing the free drug. As a result, NPs of any size can be cytotoxic, even if they release the drug only in the cytoplasm, as it can then diffuse toward the nucleus in free form.

For spheroids exposed to $5 \mathrm{~nm}$ nanoparticles we were only able to detect small aggregates of nanoparticles due to the limited resolution and contrast of the TEM analysis. Notwithstanding, by scanning the spheroid from the outer edge we were able to detect aggregates of $5 \mathrm{~nm}$ nanoparticles up to a distance of 60 - $80 \mu \mathrm{m}$, in agreement with the results obtained via reflection microscopy (SI, Figure S25).
A

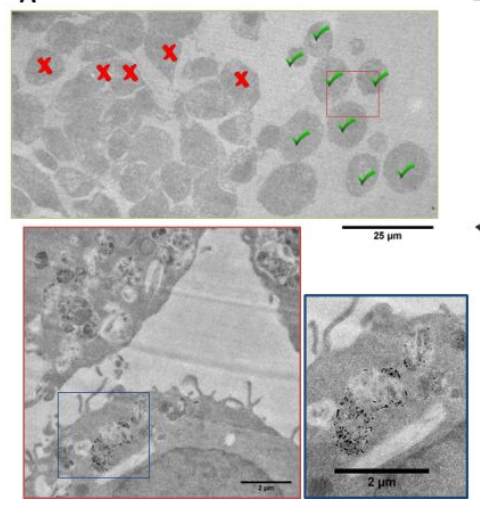

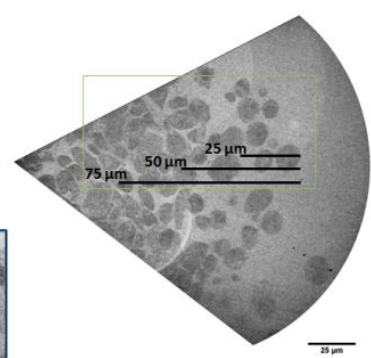

Figure 4. (A) TEM image of an ultramicrotomed spheroid slice, indicating cells which show (green ticks) or not (red crosses) the intracellular presence of Au14@MEMC. Images in the lower panel show higher magnification views of the cells. High magnification images of all indicated cells are shown in the SI. 
(B) TEM image indicating approximate NP penetration distances from the outer spheroid edge.

14 15.91 1.1 1 1

2

3

4

5

6

7

8

9
Quantitative ICP-MS analysis confirmed a higher content of $\mathrm{Au}$ NPs inside spheroids for the smaller Au2@MEMC (SI, Figure S26). The data obtained in the 2D model revealed that the cellular uptake of NPs is proportional to their size (Figure S16), therefore the ICP-MS results obtained with 3D models must be considered as an indication of the higher tumor penetrability of the smaller NPs, rather than a measurement of cellular uptake. In fact, by comparing the cellular uptake of MEMC in 2D models and 3D models, we can get a rough quantification of the sizedependent penetrability. This comparison (Figure 5) indicates that the tumor penetrability of Au2@MEMC is 5-fold greater than $14 \mathrm{~nm}$ NPs and 4-fold better than $5 \mathrm{~nm}$ NPs.

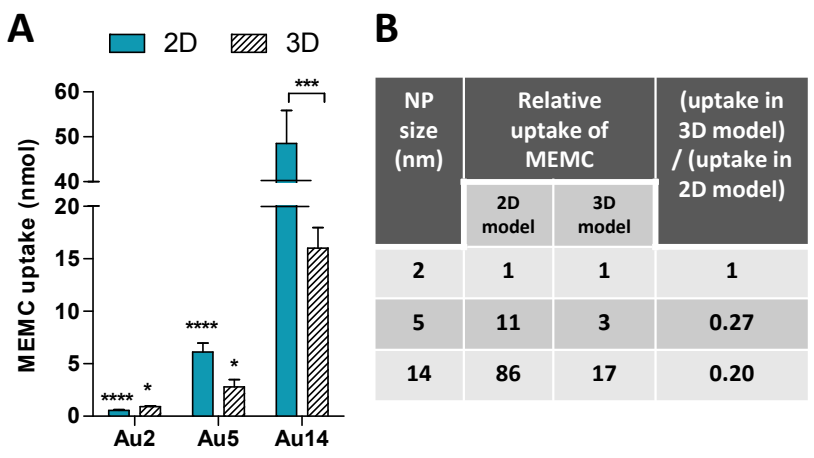

Figure 5. (A) Size-dependent uptake of MEMC (nmol) in MDA.MB.231cells, determined from ICP-MS analysis in both 2D and 3D models. (B) Relative uptake of MEMC in both cell culture models. An arbitrary value of 1 was assigned to the uptake of $2 \mathrm{~nm}$ nanoparticles in both models. 2-way ANOVA with Bonferroni post-test was used to determine any significant differences which, unless shown otherwise, were calculated against the equivalent Au14 NP condition (2D or 3D) $\left.{ }^{*} \mathrm{p} \leq 0.05,{ }^{* * *} \mathrm{p} \leq 0.001,{ }^{* * * *} \mathrm{p} \leq 0.0001\right)$.

The ICP-MS data obtained in the 3D model, together with the cytotoxicity data, also allowed us to determine the sizedependent cytotoxicity adjusted for internalized MEMC, in analogy with the analysis discussed above for the 2D model (Table 1). The results from the 3D model are in excellent agreement with those obtained previously in the 2D model. They confirm that, after internalization, MEMC bound to $2 \mathrm{~nm}$ NPs is about 20 times more cytotoxic than MEMC bound to 14 nm NPs (Table 2).

Table 2. Relative cytotoxicity of differently sized nanoparticles in 3D spheroids composed of MDA.MB.231 and HDF cells, normalized to MEMC uptake. An arbitrary value of 1 was assigned to $14 \mathrm{~nm}$ nanoparticles. The uptake of MEMC was calculated using the measurements of Au uptake by ICP-MS (Figure S26) and the calculations of drug payload (see Experimental and Table S4). The relative cytotoxicity was determined from data shown in Figure 3B.

\begin{tabular}{|c|c|c|c|c|}
\hline $\begin{array}{c}\text { Core } \\
\text { size } \\
\text { (nm) }\end{array}$ & $\begin{array}{c}\text { MEMC } \\
\text { internalized } \\
\text { per cell } \\
\text { (nmol) }\end{array}$ & $\begin{array}{c}\text { Relative } \\
\text { Cytotoxic } \\
\text { ity }\end{array}$ & $\begin{array}{c}\text { Relative } \\
\text { cytotoxicity } \\
\text { per } \\
\text { internalized } \\
\text { MEMC } \\
\text { (3D model) }\end{array}$ & $\begin{array}{c}\text { Relative } \\
\text { cytotoxicity } \\
\text { per } \\
\text { internalized } \\
\text { MEMC } \\
\text { (2D model) }\end{array}$ \\
\hline $\mathbf{2}$ & 0.92 & 1.6 & 24 & 21 \\
\hline $\mathbf{5}$ & 2.74 & 1.0 & 5 & 3 \\
\hline
\end{tabular}

By using 3D tumor models we showed that the smallest NPs can penetrate more deeply in tumor spheroids than larger Au5 and Au14 NPs, confirming previous observations of an inverse relationship between size and tumor penetrability. ${ }^{9,49}$ Spheroid penetrability was determined by using a label-free technique, reflectance imaging, developed during this work to map the distribution of $\mathrm{Au}$ NPs within the spheroids. In the next transport event, after the NPs penetrate deep into the tumor, their cellular uptake takes place. We found that MEMC uptake increases with size, so that the largest NPs (14 nm) internalize 84-fold more drug than the smaller ones, in agreement with previous research showing that optimum cellular uptake of cationic NPs is achieved with sizes ranging from 10 to 50 $\mathrm{nm} .^{32,40,50}$ In the final transport event, NPs must transport their payload to the nucleus where DNA, their biological target, is located. We compared the amount of internalized drug with the cytotoxic effect for each NP size, finding that $2 \mathrm{~nm}$ NPs are 20 times more efficient than $14 \mathrm{~nm}$ NPs in this transport event. We attribute this higher efficiency to the known ability of $2 \mathrm{~nm}$ NPs to reach the cell nucleus, a property that was confirmed by visualizing the intracellular location of the different NPs using TEM.

\section{CONCLUSIONS}

By dissecting the size effects into three transport stages (3D interstitial, cellular and nuclear transport), we provide evidence that, even though conjugates of all sizes are similarly cytotoxic, different effects are behind the cytotoxicity for each NP size. Cellular uptake of MEMC from Au14 cationic NPs is significantly more efficient than from smaller Au2 and Au5 NPs, but as these Au14 NPsare unable to reach the nucleus, they can only unload the drug in the cytoplasm. Only a fraction of this load will reach the nucleus, but efficient uptake ensures that enough MEMC reaches the DNA target. Smaller cationic Au2 NPs provide lower MEMC uptake, but as it is partly unloaded in the nucleus, local accumulation of free drug close to the target DNA occurs which results in a higher level of cytotoxicity than what would be expected for their limited drug uptake.

\section{EXPERIMENTAL}

Materials and Methods. Mitomycin $\mathrm{C}$ (in $\mathrm{NaCl}$ ) was from Sanofi-Aventis and was desalted by liquid-liquid extraction $\left(\mathrm{CH}_{2} \mathrm{Cl}_{2} / \mathrm{H}_{2} \mathrm{O}\right)$ before use. Other chemicals were purchased as reagent grade from Sigma-Aldrich and used without further purification. NE-PER Nuclear and Cytoplasmic Extraction Kit were purchased from Thermo. Mitomycin $\mathrm{A}^{51}$ and (MEMC) ${ }_{2}{ }^{39}$ were prepared as reported. UV-Vis spectra were measured in an Agilent 8453 UV-Vis diode-array spectrophotometer. Transmission electron microscopy (TEM) images were obtained in a JEOL JEM-2100F electron microscope, at an acceleration voltage of $200 \mathrm{kV}$. Samples for TEM analysis were prepared by adding a single drop $(2 \mu \mathrm{L})$ of the aqueous solution (ca. $0.1 \mathrm{mg} / \mathrm{mL}$ in milliQ water) of gold nanoparticles onto a copper grid coated with a carbon film (Electron Microscopy Sciences). The grid was left to dry in air for several hours at room temperature. Zeta potential measurements were performed in a Malvern Zetasizer 3000 HS particle size analyzer (Malvern Instruments, UK). Cell microscopy experiments were carried out using a Zeiss 880 Confocal Fluorescence microscope using Ibidi clear-bottomed 96-well microscopy plates. Milli-Q water (resistivity $18.2 \mathrm{M} \Omega \cdot \mathrm{cm}$ at 25 ${ }^{\circ} \mathrm{C}$ ) was used in all experiments. ICP-MS measurements were performed on a Thermo iCAP Q ICP-MS (Thermo Fisher 
Scientific GmbH, Bremen, Germany). A ASX-560 autosampler was coupled to the ICP-MS (CETAC Tech, Omaha,NE, USA).

Synthesis of
((carboxymethyl)disulfanyl)ethyl)mitomycin C
Triethylamine $(4 \mu \mathrm{L}, 2.9 \mathrm{mg}, 0,03 \mathrm{mmol})$ and 2-(2pyridinyldithio)ethanamine $\cdot \mathrm{HCl}(5 \mathrm{mg}, 0.024 \mathrm{mmol})$ were added to a solution of mitomycin A (7 mg, $0.020 \mathrm{mmol})$ in $\mathrm{MeOH}(0.5 \mathrm{~mL})$. The mixture was stirred at $25^{\circ} \mathrm{C}$, following the conversion of mitomycin A to a blue compound of lower retention factor (Rf) by thin-layer chromatography (TLC) $\left(\mathrm{SiO}_{2}\right.$, $5 \% \mathrm{EtOH}$ in $\mathrm{CH} 2 \mathrm{Cl} 2)$. When the disappearance of mitomycin $\mathrm{A}$ was observed ( 3 - 4 hours), sodium thioglycolate ( $3 \mathrm{mg}, 0.025$ mmol) and triethylamine ( $3 \mu \mathrm{L}, 2 \mathrm{mg}, 0,02 \mathrm{mmol}$ ) were added to the reaction mixture and stirred for $15 \mathrm{~min}$. The mixture was poured over $15 \mathrm{~mL}$ of $0.1 \mathrm{M}$ phosphate buffer ( $\mathrm{pH}$ 7.1) and extracted with $\mathrm{CHCl}_{3}(2 \times 10 \mathrm{~mL})$ to remove 2mercaptopyridine. The aqueous phase was concentrated by rotary evaporation to remove residual organic solvents. The resulting blue solution was purified in two batches using 500 mg C-18 cartridges (Sep-pak, Waters). The cartridges were pre-washed with ACN and water, the aqueous extract of the reaction mixture was then loaded, washed with water and the compound eluted with $10 \%$ ACN in water. The solution was lyophilized to yield 5 as a blue solid (5.5 mg, $0.011 \mathrm{mmol}, 55 \%$ overall yield). ${ }^{1} \mathrm{HNMR}\left(\mathrm{D}_{2} \mathrm{O}\right) \delta(\mathrm{ppm}): 2.00$ (s, $\left.3 \mathrm{H}, \mathrm{CH}_{3}-\mathrm{C} 7\right) ; 3.01$ $\left(\mathrm{t}, 2 \mathrm{H}, \mathrm{J}=6.4 \mathrm{~Hz}, \mathrm{CH}_{2} \mathrm{CH}_{2} \mathrm{~S}\right) ; 3.04(\mathrm{~m}, 1 \mathrm{H}, \mathrm{C}(2) H) ; 3.08(\mathrm{~m}, 1 \mathrm{H}$, $\mathrm{C}(1) H) ; 3.26\left(\mathrm{~s}, 3 \mathrm{H}, \mathrm{OCH}_{3}\right) ; 3.40\left(\mathrm{~s}, 3 \mathrm{H}, \mathrm{SCH}_{2} \mathrm{COOH}\right) ; 3.60-3.64$ (m, $1 \mathrm{H}, \mathrm{C}(9) H) ; 3.65$ (app. dd, $\left.1 \mathrm{H}, \mathrm{J}=4.6,10.7 \mathrm{~Hz}, \mathrm{C}(3) H_{\mathrm{a}}\right) ; 4.02$ (t, $\left.2 \mathrm{H}, \mathrm{J}=6.4 \mathrm{~Hz}, \mathrm{CH}_{2} \mathrm{NH}\right) ; 4.25\left(\operatorname{app~d}, 1 \mathrm{H}, \mathrm{J}=13.9 \mathrm{~Hz}, \mathrm{C}(10) H_{\mathrm{a}}\right)$; 4.39 (app t, 1 H, J= 11.0 Hz, C(10) $H_{\mathrm{b}}$ ); 4.63 (app. dd, $1 \mathrm{H}, \mathrm{J}=4.3$, $10.6 \mathrm{~Hz}, \mathrm{C}(3) H_{\mathrm{b}}$ ) (Figure S2 and S3). HRMS (ESI+) 485.1103 $\left([\mathrm{M}+\mathrm{H}]^{+}\right.$, calcd 485.1165) 507.1039 $\left([\mathrm{M}+\mathrm{Na}]^{+}\right.$, calcd 507.0984) 424.1008 ([M- $\left.\mathrm{NH}_{2} \mathrm{OCO}^{-}\right]^{+}$, calcd 424.0926) 991.1971 $\left([2 \mathrm{M}+\mathrm{H}]^{+}, \quad\right.$ calcd 969.2251$) \quad 991.1891 \quad\left([2 \mathrm{M}+\mathrm{Na}]^{+}, \quad\right.$ calcd 991.2071) (Figure S4 and S5). UV-vis $\left(\mathrm{H}_{2} \mathrm{O}\right) \lambda \max$ (E) 376 $\left(20000 \mathrm{M}^{-1} \mathrm{~cm}^{-1}\right)$ and $593 \mathrm{~nm}$ (Figure S6).

Synthesis of Au@PEG- $\mathbf{N H}_{2}$ Nanoparticles. Au2@PEG- $\mathrm{NH}_{2}$ : A solution of $\mathrm{SH}-\mathrm{PEG}_{2000}-\mathrm{NH}_{2}\left(22 \mathrm{mg}, 10.8 \mu \mathrm{mol}, 3\right.$ equiv) in $\mathrm{H}_{2} \mathrm{O}$ $(1.2 \mathrm{~mL})$ was added to a solution of tetrachloroauric acid (1.4 $\mathrm{mg}, 3.6 \mu \mathrm{mol}, 1$ equiv). An aqueous solution of $\mathrm{NaBH}_{4}(38 \mathrm{mM}$, $90 \mu \mathrm{L}, 3.42 \mu \mathrm{mol}$ ) was added in small aliquots under rapid stirring. The dark-brown suspension obtained was further stirred for $2 \mathrm{~h}$ and incubated at $4{ }^{\circ} \mathrm{C}$ overnight. Purification was performed by centrifugal filtration with Amicon filters $(10 \mathrm{KDa}$ MWCO), washing with water until Au NPs were free of starting material (absence of signals from PEG moieties in ${ }^{1} \mathrm{H}-\mathrm{NMR}$ spectroscopy in the washings). $\mathrm{Au}$ NPs were finally concentrated to a volume of $0.5 \mathrm{~mL}$ of water to be used for conjugation with mitomycin C derivative (5). Au5@PEG- $\mathrm{NH}_{2}$ and Au14@PEG- $\mathrm{NH}_{2}$ were prepared by surface functionalization with the bifunctional ligand $\mathrm{SH}-\mathrm{PEG}_{2000}-\mathrm{NH}_{2}$ from the corresponding Au5@citrate NPs ${ }^{52}$ and Au14@citrate NPs. ${ }^{36}$ Briefly, $167 \mu \mathrm{L}$ of a $10 \mathrm{mg} / \mathrm{mL}$ aqueous HS-PEG- $\mathrm{NH}_{2}$ solution was added to $5 \mathrm{~mL}$ of an aqueous dispension of Au5@citrate or Au14@citrate nanoparticles (0.46 mM). The reaction mixture was vortexed immediately and subsequently incubated at $4{ }^{\circ} \mathrm{C}$ overnight. Au5@PEG- $\mathrm{NH}_{2}$ and Au14@PEG$\mathrm{NH}_{2}$ were washed and purified by filter centrifugation $(10 \mathrm{KDa})$ three more times and then used for conjugation with mitomycin $\mathrm{C}$ derivative (5).

Synthesis of Au@MEMC nanoparticles. A solution of 5, NHS (150 mol\%), and EDC (150 mol\%) in $50 \mathrm{mM}$ MES (pH 6.4) was stirred at $25{ }^{\circ} \mathrm{C}$, for 15 minutes. The final concentration of activated 5 was $3 \mathrm{mM}$. A two-fold molar excess of activated acid 5 , relative to the theoretical amount of $\mathrm{NH}_{2}$ groups present in the $\mathrm{H}_{2} \mathrm{~N}$-PEG-S-NP solution, was used for the coupling reaction. The solution of activated 5 was added to the NP solution and the resulting mixture was stirred for $24 \mathrm{~h}$. The modified NPs were purified using centrifugal filters with a MWCO of $50 \mathrm{kDa}$ (for $5 \mathrm{~nm}$ and $14 \mathrm{~nm} \mathrm{NPs}$ ) or MWCO $10 \mathrm{kDa}$ (for $2 \mathrm{~nm} \mathrm{NPs}$ ), as follows: The reaction mixtures were diluted to $4 \mathrm{~mL}$ with water (for $5 \mathrm{~nm}$ and $14 \mathrm{~nm} \mathrm{NPs}$ ) or $\mathrm{MeOH} / \mathrm{H}_{2} \mathrm{O}$ 1:1 (for $2 \mathrm{~nm} \mathrm{NPs}$ ), loaded onto the filter and centrifuged until the volume was reduced down to $200-400 \mu \mathrm{L}$. The concentrated NP solutions were diluted again to $4 \mathrm{~mL}$ and centrifuged. This process was repeated until the filtrate showed no presence of the mitomycin chromophore when analyzed by UV-vis spectroscopy (usually five washes were needed). The yields of the coupling reaction were 12\% for of Au2@MEMC, 15\% for of Au5@MEMC and 10\% for of Au14@MEMC, as calculated from the drug payload determined by UV-vis spectroscopy (vide infra).

Quantification of drug payload. The amounts of drug loaded onto Au@MEMC were quantified using UV-vis spectroscopy and HPLC. Quantification by UV-vis was performed by subtracting the spectrum of Au@PEGNH ${ }_{2}$ from that of Au@MEMC. The concentration of MEMC was calculated from absorbance measurements at $376 \mathrm{~nm}$, using an extinction coefficient of $20000 \mathrm{M}^{-1} \mathrm{~cm}^{-1}$.

Quantification of the concentration of nanoparticles. The concentration of Au@MEMC nanoparticles was quantified using UV-vis spectroscopy. This measurement was performed with the UV spectrum of Au@PEGNH2 used as subtracted in the experimental protocol described above. The concentration of nanoparticles was calculated using the absorbance at $506 \mathrm{~nm}$. The extinction coefficients were calculated with a function generated from published data, ${ }^{53}$ and they were as follows: $\varepsilon$ $\left(\mathrm{M}^{-1} \mathrm{~cm}^{-1}\right) \quad 4.74 \cdot 10^{5}(2 \mathrm{~nm}), 9.96 \cdot 10^{6}(5 \mathrm{~nm})$ and $3.05 \cdot 10^{8}(14$ $\mathrm{nm})$.

Quantification of the number of MEMC molecules per nanoparticle. The data from the two quantification experiments described above was used to calculate the number of MEMC molecules per nanoparticle. The results were as follows: (number of MEM molecules) $30(2 \mathrm{~nm}), 224(5 \mathrm{~nm})$, $1400(14 \mathrm{~nm})$.

Release of MEMC or its metabolites from Au@MEMC. A solution of Au@MEMC was treated with disulfide-reducing agents (DTT, GSH or TCEP), incubated for at least 2 hours, and analyzed by LC/MS. The identity of some of the peaks observed in the chromatograms was determined by UV-vis spectroscopy and ESI-MS. Samples treated with DTT showed the release of MEMC (5). Samples treated with GSH gave MEMC (5): HRMS $(\mathrm{ESI}+) 395.1051\left([\mathrm{M}+\mathrm{H}]^{+}\right.$, calcd 395.1389) $417.0854\left([\mathrm{M}+\mathrm{Na}]^{+}\right.$, calcd 417.1209) $334.0915\left(\left[\mathrm{M}-\mathrm{NH}^{2} \mathrm{OCO}^{-}\right]^{+}\right.$, calcd 334.1220) $302.0665\left(\left[\mathrm{M}-\mathrm{NH}_{20 C O}-\mathrm{CH}_{3} \mathrm{OH}\right]^{+}\right.$, calcd 302.0958) 811.1819 $\left([2 \mathrm{M}+\mathrm{Na}]^{+}\right.$, calcd 811.2520). UV-VIS (H2O) $\lambda \max 376 \mathrm{~nm} ;(11)$ HRMS (ESI+) $611.1942\left([\mathrm{M}+\mathrm{H}]^{+}\right.$, calcd 611.1958). Samples treated with TCEP gave 4 major peaks. Data for the peak at 2.4 min (12 or 13): HRMS (ESI+) 570.1852 ([M $]^{+}$, calcd 570.1670). Data for the peaks at 8.0 and $8.3 \mathrm{~min}$ (14). HRMS (ESI+) 552.1744 and $552.1760\left([\mathrm{M}]^{+}\right.$, calcd 552.1569).

Analysis of NP cytotoxicity in 2D cell cultures. The human breast cancer cell line MDA.MB.231 and human dermal fibroblasts (HDF) (purchased from ATCC and Invitrogen respectively) were grown in DMEM media supplemented with $10 \%$ fetal bovine serum (FBS) (both Invitrogen). Cells were routinely checked for mycoplasma presence using the MycoAlert assay (Lonza). 10,000 MDA.MB.231 and HDF cells/well were plated separately in 96-well plates and allowed 
to adhere. The following day the cell media was replaced with $100 \mu \mathrm{L}$ of serially diluted solutions of NPs, with (Au@MEMC conjugates) and without MEMC (Au@PEGNH $\mathrm{H}_{2}$ ), added at a starting highest MEMC concentration of $2.5 \mu \mathrm{M}$ MEMC or equivalent $\mathrm{Au}$ concentration in samples without MEMC. Samples were incubated for $24 \mathrm{~h}$ at $37^{\circ} \mathrm{C}$ and the cell viability determined using the MTT assay (Roche), reading the absorbance at $550 \mathrm{~nm}$.

Cell uptake Inhibition Study. MDA.MB.231 and HDF cells lines were plated at $1 \times 10^{4}$ cells/well $\left(1 \times 10^{5}\right.$ cells $\left./ \mathrm{ml}\right)$ and allowed to adhere overnight. Chloropromazine (30mM stock, added at a final concentration of $7.5 \mu \mathrm{M})$, Cytochalasin D ( $4 \mathrm{mM}$ stock, added at a final concentration of $1 \mu \mathrm{M}$ ), and Methyl-betacyclodextrin (stock $100 \mathrm{mg} / \mathrm{ml}$, added at a final concentration of $2 \mathrm{mg} / \mathrm{ml}$ ) inhibitors were added to cells in FBS-free DMEM, $100 \mathrm{ul} /$ well. After $30 \mathrm{~min}, 50 \mu \mathrm{L}$ of each inhibitor was removed and replaced with the different sized Au NPs $(1 \mu \mathrm{M}$ solution in FBS-containing DMEM). The final concentration of NP with the cells was therefore $0.5 \mu \mathrm{M}$, once the dilution with the inhibitor was taken into account. NPs were left in contact with the cells for $4 \mathrm{~h}$, followed by removal of the supernatant, washing with PBS, and cell dissociation from the plate using trypsin. Both the cell supernatant (containing non-uptaken NPs) and the cell pellets (containing uptaken NPs) were analysed using ICP to determine the amount of AuNPs present.

Fragmentation of Cell Nuclei and Cytoplasm and ICP quantification. MDA.MB.231 cells were plated in 24-well plates at a concentration of $8 \times 10^{4}$ cells $/ \mathrm{mL}, 500 \mu \mathrm{L} /$ well. Cells were allowed to adhere overnight. Media was replaced with $300 \mu \mathrm{L}$ of NPs (final concentration $0.5 \mu \mathrm{M}$ ). After $6 \mathrm{~h}$, supernatants were removed and stored on ice, and cells were dissociated with Trypsin from the plate and each NP containing well was pooled with a non-NP containing well to increase the cellular mass. The cells were washed with PBS (500 g, $4{ }^{\circ} \mathrm{C}$, $5 \mathrm{~min}$ ) and then the initial part of the NE-PER Nuclear and Cytoplasmic Extraction Kit (Thermo) was followed. Briefly, the cell cytoplasm and nucleus were separated using the aforementioned commercial reagents with centrifugation at $16,000 \mathrm{~g}$. Samples were stored on ice between washes. Both nuclei and cytoplasm were processed for ICP-MS analysis.

Quantitative analysis of NP cytotoxicity in 3D cell cultures. Spheroids were produced using round-bottomed ultralow attachment 96-well microplates (Corning). MDA.MB.231 and HDF cells were suspended in DMEM media containing 5\% FBS and combined at a ratio of 1:2 (cancer:fibroblast). $200 \mu \mathrm{L}$ of mixed cells were seeded in the microplates (3120 cells/well), and the spheroids were left to form undisturbed over $48 \mathrm{~h}$. To add the Au@MEMC conjugates NPs, media was replaced with $100 \mu \mathrm{L}$ of NPs in 5\% FBS/DMEM, added at a final MEMC concentration of $0.5 \mu \mathrm{M}$ or equivalent $\mathrm{Au}$ concentration in samples without MEMC. Spheroids were left undisturbed for 48 $\mathrm{h}$ at $37^{\circ} \mathrm{C}$. To determine the cell viability, spheroids were gently washed with media and transferred to white walled microplates. An equal volume of CellTiter-Glo 3D cell viability solution (Promega) was added and the plate shaken for $5 \mathrm{~min}$ followed by a $25 \mathrm{~min}$ period without shaking, at RT. The luminescence was read using a $1 \mathrm{~s}$ integration time.

Fluorescence microscopy of NP treated spheroids. Visual determination of the cell viability was conducted using spheroids grown and treated with NPs as described above. After a $48 \mathrm{~h}$ incubation period, spheroids were washed and stained with Live-Dead Cell Staining kit (Abcam; a mix of Propidium iodine and propriety live marker). The spheroids were observed using a confocal fluorescence microscope (Zeiss
880), with excitation lasers at $488 \mathrm{~nm}$ and $561 \mathrm{~nm}$ (live and dead fluorophores respectively). All images were taken at the same z-height $(80 \mu \mathrm{m})$ using a $20 \times$ objective $(0.8$ N.A). The area of the spheroids at this z-height was calculated to control for differences in fluorophore penetration that may occur due to the spheroid diameter. Image acquisition and post processing was identical for all spheroids and included a 3-pixel median filter. To quantify penetration of propidium iodide in the spheroids a region of interest (ROI) was drawn from that raw images and the corrected total fluorescence (CTF) calculated.

Quantification of NP uptake by spheroids. ICP-MS, reflectance microscopy and TEM were used to quantify NP uptake in spheroids, as described below.

Reflectance Microscopy: The same live-dead stained spheroids were used (see above). After taking images showing the penetration of dead-stain into spheroids, the spheroids were fixed using 4\% formaldehyde (15 min RT) and mounted on a glass slide with double sided sticky tape to create a small chamber. Samples were viewed using a Zeiss 880 confocal scanning microscope equipped with a $10 \times$ objective (NA, 0.45 ) and reflectance images obtained using $633 \mathrm{~nm}$ excitation with a $38 \mu \mathrm{m}$ pinhole, and a $23 \mathrm{~nm}$ detector window set from 622 to $645 \mathrm{~nm}$. Images taken at the same z-height were compared (to do this we selected images of the same z-height from the maximum reflection obtained, relating to the reflection of the glass slide). All images were acquired using the same settings $(1024 \times 1024$ pixels, $498.5 \mu \mathrm{m} \times 498.5 \mu \mathrm{m}, 16$-bit, $10.07 \mathrm{~s} /$ frame). Images were then processed using selfdeveloped routines for the NIH free provided software ImageJ $\subset .^{54}$ To do so, radial profiles of reflection signal intensity vs. pixel distance from the center of the spheroid were acquired at $5^{\circ}$ intervals. The radial profiles for each spheroid where averaged together; the approximate radius of each spheroid was measured and background values lying outside of the spheroid were removed (usually $\sim 300$ pixels measured from the center). Assuming a normal distribution of the particles, the values were fitted to a Gaussian curve (see equation below), and based on the distribution, the initial 10 - 20 pixels (relating to the center of the spheroid) were removed if they did not fit with the curve. Formula: $\left.y=a+(b-a)^{*} \exp \left(-(x-c)^{\wedge} 2\right) /\left(2^{*} d^{\wedge} 2\right)\right)$ The value of $\mathrm{c}-\mathrm{d}$ (center of the peak, $\mathrm{c}$, minus the standard deviation, d), subtracted from the average spheroid radius, was assumed to represent the average maximum distance that the NPs had penetrated from the spheroid edge. These values were translated into microns using the scale in the original image $(1024$ pixels $=498.46 \mu \mathrm{m})$. Due to differences in the maximum intensity of the reflection between spheroids, all samples were normalized to the change in the minimum and maximum intensity of the non-NP containing spheroids.

TEM: Spheroids were also analyzed by TEM to determine the ability of the different sized NPs to penetrate inside the spheroids. For ease of handling, larger spheroids were made with 4 times larger number of cells (12,500 cells/well). All other conditions remained the same (spheroid growth time, NP concentrations, incubation time, etc.). After $48 \mathrm{~h}$ incubation of spheroids with $\mathrm{Au}$ NPs, with (Au@MEMC conjugates) and without MEMC (Au@PEGNH $\left.{ }_{2}\right)$, spheroids were washed with Sorensen's buffer ( $0.1 \mathrm{M})$ and fixed with a $2 \%$ formaldehyde / $2.5 \%$ glutaraldehyde solution in Sorensen's buffer, initially for $10 \mathrm{~min}$ at RT, followed by replacement of the fixing solution and incubation at $4{ }^{\circ} \mathrm{C}$ for $4 \mathrm{~h}$. Samples were washed with Sorensen's buffer, stained with $1 \% \mathrm{OsO}_{4}$, dehydrated and embedded in Spurr's resin. Once polymerized, $80 \mathrm{~nm}$ slices were cut using an ultramicrotome. Samples were imaged using TEM (JEOL JEM-1400PLUS, 40-120 kV). In order to detect 2nm 
$\mathrm{Au}$ NPs in cells, silver enhancement was used on postembedded samples following the manufacturer's protocol (Aurion R-Gent SE-EM; Aurion, The Netherlands).

ICP-MS: ICP-MS analysis was conducted using spheroids made using the same method described above for 2D uptake studies. Spheroids were left to form undisturbed for $48 \mathrm{~h}$, followed by replacement of the existing medium with NP-containing medium. NPs were added at a final concentration of $5 \mu \mathrm{M}$ and incubated for $48 \mathrm{~h}$. To process the samples, free NPs were removed by washing the spheroids with PBS, and the spheroids were transferred to Eppendorf tubes containing $200 \mu \mathrm{L}$ PBS and frozen overnight. These cell samples were then digested in aqua regia $\left(3: 1 \mathrm{HNO}_{3} / \mathrm{HCl}, \mathrm{v} / \mathrm{v}\right)$ for $24 \mathrm{~h}$, diluted with $2 \% \mathrm{HNO}_{3}$ and then subjected to ICP-MS analysis.

\section{ASSOCIATED CONTENT}

\section{Supporting Information}

The Supporting Information is available free of charge on the ACS Publications website.

(Data)

\section{AUTHOR INFORMATION}

\section{Corresponding Authors}

*E-mail: manuel.paz@usc.es

*E-mail: llizmarzan@cicbiomagune.es

\section{Notes}

The authors declare no competing financial interest.

\section{ACKNOWLEDGMENT}

This work has been funded by MINECO (Grant MAT201786659-R). We greatly appreciate the support by Pedro Ramos Cabrer in the analysis of reflectance images.

\section{REFERENCES}

(1) Din, F., Aman, W., Ullah, I., Qureshi, O. S., Mustapha, O., Shafique, S., and Zeb, A. (2017) Effective use of nanocarriers as drug delivery systems for the treatment of selected tumors. Int. J. Nanomedicine 12, 7291-7309.

(2) Sperling, R. A., Rivera Gil, P., Zhang, F., Zanella, M., and Parak, W. J. (2008) Biological applications of gold nanoparticles. Chem. Soc. Rev. 37, 1896-1908.

(3) Ghosh, P., Han, G., De, M., Kim, C. K. and Rotello, V. M. (2008) Gold nanoparticles in delivery applications. Adv. Drug Deliv. Rev. 60, 13071315.

(4) Boisselier, E., and Astruc, D. (2009) Gold nanoparticles in nanomedicine: preparations, imaging, diagnostics, therapies and toxicity. Chem. Soc. Rev. 38, 1759-1782.

(5) Kim, C., Ghosh, P., and Rotello, V. M., (2009) Multimodal drug delivery using gold nanoparticles. Nanoscale 1, 61-67.

(6) Liz-Marzán, L. M. (2015) Increasing Complexity while Maintaining a High Degree of Symmetry in Nanocrystal Growth. Angew. Chem. Int. Ed. 54, 3860-3861.

(7) Libutti, S. K., Paciotti, G. F., Byrnes, A. A., Alexander, H. R., Gannon, W. E., Walker, M., Seidel, G. D., Yuldasheva, N., and Tamarkin, L. (2010) Phase I and pharmacokinetic studies of CYT-6091, a novel PEGylated colloidal gold-rhTNF nanomedicine. Clin. Cancer Res. 16, 6139-6149.

(8) Huo, S., Jin, S., Ma, X., Xue, X., Yang, K., Kumar, A., Wang, P. C., Zhang, J., Hu, Z., and Liang, X. J. (2014) Ultrasmall gold nanoparticles as carriers for nucleus-based gene therapy due to size-dependent nuclear entry. ACS Nano 8, 5852- 5862.

(9) Huang, K., Ma, H., Liu, J., Huo, S., Kumar, A., Wei, T., Zhang, X., Jin, S., Gan, Y., Wang, P. C., He, S., Zhang, X., and Liang, X.-J. (2012) Sizedependent localization and penetration of ultrasmall gold nanoparticles in cancer cells, multicellular spheroids, and tumors in vivo. ACS Nano 6, 4483- 4493.

(10) Feldherr, C. M. and Akin, D. (1990) EM visualization of nucleocytoplasmic transport processes. Electron Microsc. Rev. 3, 73-86.

(11) Dworetzky, S. I., Lanford R. E., and Feldherr, C. M. (1988) The Effects of Variations in the Number and Sequence of Targeting Signals on Nuclear Uptake. J. Cell Biol. 107, 1279-1287.

(12) Zhang, X., Shastry, S., Bradforth, S. E. and Nadeau, J. L. (2015) Nuclear uptake of ultrasmall gold-doxorubicin conjugates imaged by fluorescence lifetime imaging microscopy (FLIM) and electron microscopy. Nanoscale 7, 240-251.

(13) Missailidis, S. (2008) Ed., Anticancer Therapeutics, John Wiley \& Sons, Ltd., Chichester, UK.

(14) Farmer, P. B. (1987) Metabolism and Reactions of Alkylating Agents. Pharmacol. Ther. 35, 301-357.

(15) Bradner, W. T., (2001) Mitomycin C: a clinical update. Cancer Treat. Rev. 27, 35-50.

(16) Paz, M. M., and Pritsos, C. A. (2012) The Molecular Toxicology of Mitomycin C. Adv. Mol. Toxicol. Vol. 6 (Fishbein, J. C., Eds.) pp 244-286, Elsevier B.V, Amsterdam

(17) Hartigh, J. den., McVie, J. G., van Oort, W. J., and Pinedo, H. M. (1983) Pharmacokinetics of Mitomycin C in Humans. Cancer Res. 43, 5017-5021.

(18) Iyer, V. N., and Szybalski, W. (1964) Mitomycins and porfiromycin: chemical mechanism of activation and crosslinking of DNA. Science 145, 55-58.

(19) Penketh, P. G., Hodnick, W. F., Belcourt, M. F., Shyam, K., Sherman, D. H., and Sartorelli, A. C. (2001) Inhibition of DNA Crosslinking by Mitomycin $\mathrm{C}$ by Peroxidase-mediated Oxidation of Mitomycin C Hydroquinone. J. Biol. Chem. 276, 34445-34452.

(20) Siegel, D., Beall, H., Senekowitsch, C., Kasai, M., Arai, H., Gibson, N. W., and Ross, D. (1992) Bioreductive activation of mitomycin C by DT-diaphorase. Biochemistry 31, 7879- 7885.

(21) Seow, H. A., Belcourt, M. F., Penketh, P. G., Hodnick, W. F., Tomasz, M., Rockwell, S., and Sartorelli, A. C. (2005) Nuclear Localization of NADPH:Cytochrome $c$ (P450) Reductase Enhances the Cytotoxicity of Mitomycin C to Chinese Hamster Ovary Cells. Mol. Pharmacol. 67, 417-423.

(22) Holtz, K. M., Rockwell, S., Tomasz, M., and Sartorelli, A. C. (2003) Nuclear Overexpression of NADH:Cytochrome $b_{5}$ Reductase Activity Increases the Cytotoxicity of Mitomycin C (MC) and the Total Number of MC-DNA Adducts in Chinese Hamster Ovary Cells. J. Biol. Chem. 278, 5029-5034.

(23) Blanco, E., Shen, H., and Ferrari, M., (2015) Principles of nanoparticle design for overcoming biological barriers to drug delivery. Nat. Biotechnol. 33, 941-951.

(24) Kobayashi, E., Okabe, M., Kono, M., Arai, H., Kasai, M., Gomi, K., Lee, J. H., Inaba, M., and Tsuruo, T. (1993) Comparison of uptake of mitomycin C and KW-2149 by murine P388 leukemia cells sensitive or resistant to mitomycin C. Cancer Chemother. Pharmacol. 32, 20-24.

(25) Dirix, L., Catimel, G., Verdonk, R., De Bruijn, E., Tranchand, B., Ardiet, C., and Van Oosterom, A. (1995) Phase I and pharmacokinetic study of KW-2149 given by 24 hours continuous infusion. Invest. New Drugs 13, 133-136.

(26) Macaulay, V. M., O’Byrne, K. J., Green, J. A., Philip, P. A., McKinley, L., LaCreta, F. P., Winograd, B., Ganesan, T. S., Harris, A. L. and Talbot, D. C. (1988) Phase I study of the mitomycin C analogue BMS-181174. Br. J. Cancer 77, 2020-2027.

(27) Leamon, C. P., Reddy, J. A., Vlahov, I. R., Vetzel, M., Parker, N., Nicoson, J. S., Xu, L.-C. C., and Westrick, E. (2005) Synthesis and Biological Evaluation of EC72: A New Folate-Targeted Chemotherapeutic. Bioconj. Chem. 16, 803-811.

(28) Vlahov, I. R., Santhapuram, H. K. R., Wang, Y., Kleindl, P. J., You, F., Howard, S. J., Westrick, E., Reddy J. A. and Leamon, C. P., (2007) An Assembly Concept for the Consecutive Introduction of Unsymmetrical Disulfide Bonds: Synthesis of a Releasable Multidrug Conjugate of Folic Acid. J. Org. Chem. 72, 5968- 5972.

(29) He, Q.-Y., Maruenda, H., and Tomasz, M. (1994) Reductive Activation of Mitomycin A by Thiols. J. Am. Chem. Soc. 116, 9349- 9349.

(30) Saito, G., Swanson, J. A., and Lee, K. D., (2003) Drug delivery strategy utilizing conjugation via reversible disulfide linkages: role and site of cellular reducing activities. Adv. Drug Deliv. Rev. 55, 199-215.

(31) Hong, R., Han, G., Fernández, J. M., Kim, B. J., Forbes, N. S., and Rotello, V. M. (2006) Glutathione-mediated delivery and release using 
monolayer protected nanoparticle carriers. J.Am. Chem. Soc. 128, 1078 1079.

(32) Jiang, Y., Huo, S., Mizuhara, T., Das, R., Lee, Y. W., Hou, S., Moyano, D. F., Duncan, B., Liang, X. J., and Rotello, V. M. (2015) The Interplay of Size and Surface Functionality on the Cellular Uptake of Sub-10 nm Gold Nanoparticles. ACS Nano 9, 9986-9993.

(33) Kono, M., Saitoh, Y., Kasai, M., Shirahata, K., Morimoto, M., and Ashizawa, T. (1993) Synthesis and structure-activity relationships of new dimeric mitomycin derivatives; 7-N,7'-N'-bis(omegathioalkyl)dimitomycins. J. Antibiot. 46, 1428-1438.

(34) Brust, M., Fink, J., Bethell, D., Schiffrin, D. J., and Kiely, C., (1995) Synthesis and reactions of functionalised gold nanoparticles. Chem. Commun. 16, 1655-1656.

(35) Jana, N. R., Gearheart, L., Murphy, C. J., (2001) Wet Chemical Synthesis of High Aspect Ratio Cylindrical Gold Nanorods. J. Phys. Chem. $B$ 105, 4065 .

(36) Turkevich, J., Stevenson, P. C., and Hillier, J. (1951) A study of the nucleation and growth processes in the synthesis of colloidal gold. Discuss. Faraday Soc. 11, 55-75.

(37) Pozzi, D., Colapicchioni, V., Caracciolo, G., Piovesana, S., Capriotti, A. L., Palchetti, S., De Grossi, S., Riccioli, A., Amenitsch, H., and Laganà, A. (2014) Effect of polyethyleneglycol (PEG) chain length on the bio-nano-interactions between PEGylated lipid nanoparticles and biological fluids: from nanostructure to uptake in cancer cells. Nanoscale 6, 2782- 2792.

(38) Schöttler, S., Becker, G., Winzen, S., Steinbach, T., Mohr, K., Landfester, K., Mailänder, V., and Wurm, F. R., (2016) Protein adsorption is required for stealth effect of poly(ethylene glycol)- and poly(phosphoester)-coated nanocarriers. Nat. Nanotechnol. 11, 372 377.

(39) Na, Y., Wang, S., and Kohn, H., (2002) 7-N(Mercaptoalkyl)mitomycins: Implications of Cyclization for Drug Function. J. Am. Chem. Soc. 124, 4666-4677.

(40) Chithrani, B. D., Ghazani A. A., and Chan, W. C., (2006) Determining the size and shape dependence of gold nanoparticle uptake into mammalian cells. Nano Lett. 6, 662-668.

(41) Walkey, C. D., Olsen, J. B., Guo, H., Emili, A., and Chan, W. C. (2012) Nanoparticle size and surface chemistry determine serum protein adsorption and macrophage uptake. J. Am. Chem. Soc. 134, 2139- 2147.

(42) Khanna, S., Bhatt, A. N., Dwarakanath, B. S., Rodrigues, T., Kundu, B., Silva-Correia, J., Kundu, S.C., Oliveira, J. M., Reis, R. L., and Correlo, V. M. (2018) Emerging tumor spheroids technologies for 3D in vitro cancer modeling. Pharmacol. Ther. 184, 201-211.
(43) Lu, H., and Stenzel, M. H. (2018) Multicellular Tumor Spheroids (MCTS) as a 3D In Vitro Evaluation Tool of Nanoparticles. Small 14, e1702858.

(44) Majety, M., Pradel, L. P., Gies, M., and Ries, C. H., (2015) Fibroblasts Influence Survival and Therapeutic Response in a 3D CoCulture Model. PLoS One 10, e0127948.

(45) Amann, A., Zwierzina, M., Gamerith, G., Bitsche, M., Huber, J. M. Vogel, G. F., Blumer, M., Koeck, S., Pechriggl, E. J., Kelm, J. M., et al. (2014) Development of an Innovative 3D Cell Culture System to Study Tumour - Stroma Interactions in Non-Small Cell Lung Cancer Cells. PLoS One 9 e0092511.

(46) Castillo, L. R. C., Oancea, A. D., Stüllein, C., and RégnierVigouroux, A. (2016) Inherent aggressive character of invasive and non-invasive cells dictates the in vitro migration pattern of multicellular spheroid. Sci. Rep. 6, 28375- 28387.

(47) Kim, C. S., Li, X., Jiang, Y., Yan, B., Tonga, G. Y., Ray, M., Solfiell, D. J., and Rotello, V. M. (2015) Cellular imaging of endosome entrapped small gold nanoparticles. MethodsX 2, 306-315.

(48) Martínez-Banderas, A. I., Aires, A., Teran, F. J., Perez, J. E., Cadenas, J. F., Alsharif, N., Ravasi, T., Cortajarena, A. L. and Kosel, J. (2016) Functionalized magnetic nanowires for chemical and magnetomechanical induction of cancer cell death, Sci. Rep. 6, 35786-35786.

(49) Cabral, H., Matsumoto, Y., Mizuno, K., Chen, Q., Murakami, M., Kimura, M., Terada, Y., Kano, M.R., Miyazono, K., Uesaka, M., et al. (2011) Accumulation of sub-100 nm polymeric micelles in poorly permeable tumours depends on size. Nat. Nanotechnol. 6, 815-823.

(50) Jiang, W., Kim, B. Y. S., Rutka, J. T., and Chan, W. C. W., (2008) Nanoparticle-mediated cellular response is size-dependent. Nat Nanotechnol. 3, 145-150.

(51) Vyas, D. M., Benigni, D., Partyka, R. A., Doyle, T. W., (1986) A practical synthesis of mitomycin A and its analogs. J. Org. Chem. 51, 4307-4309.

(52) Jana, N. R., Gearheart, L., Murphy, C. J., (2001) Seeding Growth for Size Control of 5-40 nm Diameter Gold Nanoparticles. Langmuir 17 6782-6786.

(53) Liu, X., Atwater, M., Wang, J., and Huo, Q., (2007) Extinction coefficient of gold nanoparticles with different sizes and different capping ligands. Colloid Surf. B Biointerfaces 58, 3-7.

(54) Schneider, C. A., Rasband, W. S., and Eliceiri, K. W. (2012) NIH Image to ImageJ: 25 years of image analysis. Nat. Methods 9, 671-675. 
Table of Contents Graphic

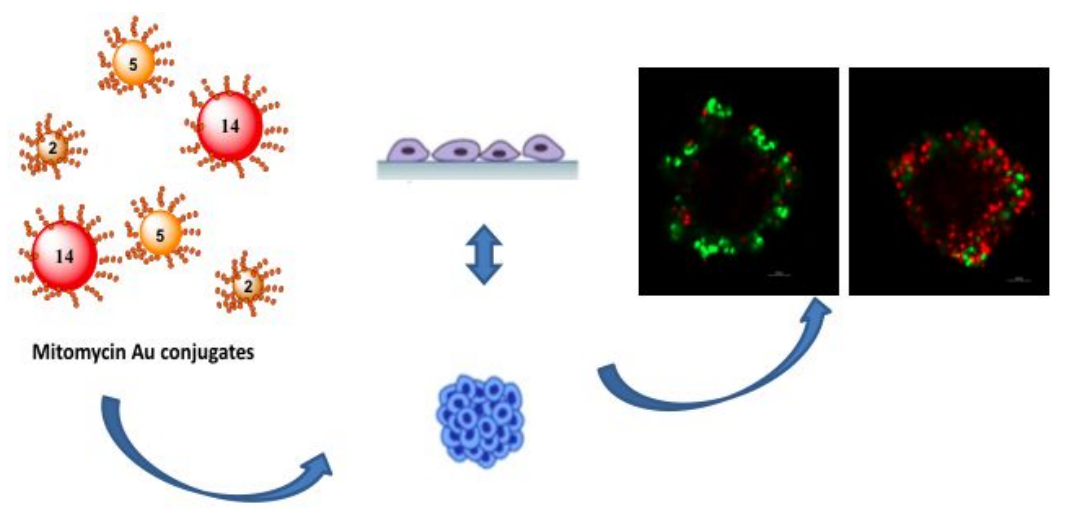

